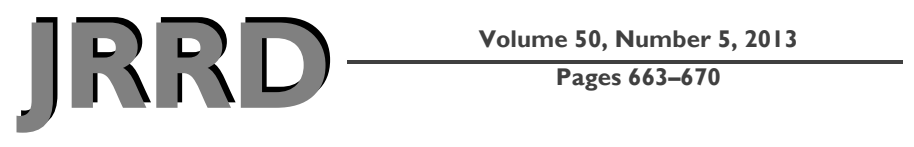

\title{
Veterans Health Administration vocational services for Operation Iraqi Freedom/Operation Enduring Freedom Veterans with mental health conditions
}

\author{
Elizabeth W. Twamley, PhD; ${ }^{1-2 *}$ Dewleen G. Baker, MD; ${ }^{1-2}$ Sonya B. Norman, PhD; ${ }^{1-2}$ James O. E. Pittman, \\ MSW; ${ }^{1}$ James B. Lohr, MD; ${ }^{1-2}$ Sandra G. Resnick, PhD ${ }^{3}$ \\ ${ }^{1}$ Center of Excellence for Stress and Mental Health, Department of Veterans Affairs (VA) San Diego Healthcare System, \\ San Diego, CA; ${ }^{2}$ Department of Psychiatry, University of California, San Diego, CA; ${ }^{3}$ New England Mental Illness \\ Research, Education, and Clinical Center, VA Connecticut Healthcare System, West Haven, CT; and Department of Psychi- \\ atry, Yale University, New Haven, CT
}

\begin{abstract}
High rates of mental health conditions and unemployment are significant problems facing Veterans of Operation Iraqi Freedom/Operation Enduring Freedom (OIF/OEF). We examined two national Veterans Health Administration (VHA) databases from fiscal years 2008-2009: a larger database $(n=$ $75,607)$ of OIF/OEF Veterans with posttraumatic stress disorder, depression, substance use disorder, or traumatic brain injury (TBI) and a smaller subset $(n=1,010)$ of those Veterans whose employment was tracked during their participation in VHA vocational services. Only $8.4 \%$ of Veterans in the larger database accessed any vocational services and retention was low, with most Veterans attending one or two appointments. Veterans with TBI and with more mental health conditions overall were more likely to access vocational services. Only $2.2 \%$ of Veterans received evidence-based supported employment. However, supported employment was effective, with $51 \%$ of those Veterans receiving it obtaining competitive work. Effect sizes quantifying the effect of supported employment provision on competitive work attainment, number of jobs, job tenure, and retention in vocational services were large. Given the high success rate of supported employment for these Veterans, additional supported employment specialists for this population would be expected to improve work outcomes for post-9/11 Veterans who want assistance returning to work.
\end{abstract}

Key words: brain injury, compensated work therapy, depression, employment, posttraumatic stress disorder, rehabilitation, service utilization, substance use disorder, supported employment, unemployment.

\section{INTRODUCTION}

Veterans of Operation Iraqi Freedom/Operation Enduring Freedom (OIF/OEF) are returning with high rates of mental health disorders such as posttraumatic stress disorder (PTSD), depression, substance use disorders, and sequelae of traumatic brain injury (TBI). Of 289,328 OIF/ OEF Veterans who enrolled in Veterans Health Administration (VHA) services from 2002 to 2008,37 percent received mental health diagnoses, including 22 percent

Abbreviations: AITC $=$ Austin Information and Technology Center, CWT $=$ Compensated Work Therapy, $d f=$ degrees of freedom, FY = fiscal year, ICD-9 = International Statistical Classification of Diseases and Related Health Problems-9, IT = Incentive Therapy, NEPEC $=$ Northeast Program Evaluation Center, OIF/OEF = Operation Iraqi Freedom/Operation Enduring Freedom, PTSD = posttraumatic stress disorder, TBI = traumatic brain injury, TWE $=$ Transitional Work Experience, $\mathrm{VA}=$ Department of Veterans Affairs, VHA = Veterans Health Administration.

*Address all correspondence to Elizabeth W. Twamley, PhD; Center of Excellence for Stress and Mental Health, VA San Diego Healthcare System, 3350 La Jolla Village Dr (116A), San Diego, CA 92161; 858-642-3848; fax: 858-6421243. Email: elizabeth.twamley@va.gov

http://dx.doi.org/10.1682/JRRD.2012.08.0137 
with PTSD, 17 percent with depression, and 10 percent with substance use disorders [1]. Approximately 20 percent of OIF/OEF Veterans have sustained a mild TBI, considered the hallmark injury of OIF/OEF [2-3]. These top four mental health conditions can limit readiness for civilian employment, as well as contribute to impaired job performance among those working [4].

Available data show that returning OIF/OEF Veterans have considerably higher unemployment rates than people in the general population. The most recent Bureau of Labor Statistics data show that, as of December 2011, the unemployment rate among OIF/OEF Veterans was 13.1 percent, compared with 8.1 percent in the non-Veteran population; these statistics do not include the 18.9 percent of OIF/OEF Veterans considered "not in the labor force" because they have stopped looking for work or are attending school [5]. Although there have been no epidemiological surveys of unemployment among Veterans with mental health conditions, we expect that rates of unemployment in this Veteran population are even higher because mental health conditions in the general population are associated with three to five times higher rates of unemployment [6]. Thus, while most OIF/OEF Veterans are young adults at a developmental stage emphasizing work and career development, many are experiencing unemployment and concomitant mental health challenges that may contribute toward their unemployment.

With high rates of mental health conditions and unemployment and the overrepresentation of Veterans in the homeless population [7], effective vocational services to help Veterans return to the workforce and increase income are urgently needed. Homeless Veterans cite mental health treatment and job assistance in their top six unmet needs [7]. VHA has provided vocational services within its mental health programs since 1976, guided by the concept of work as a bridge to recovery from the effects of mental health disorders and a necessary role in the adult development stage of life. There are currently over 175 individual Compensated Work Therapy (CWT) program locations in each of the 141 VHA healthcare systems across the nation. Supported employment, the evidence-based practice for helping people with mental health disorders return to competitive work [8-10], was disseminated in the VHA beginning in 2004 [11] and is now a mainstay of VHA care. Supported employment, which in VHA has a target population of Veterans with symptoms of psychosis, involves rapid job searching for competitive jobs in an integrated vocational and mental health treatment model [12]. Vocational rehabilitation approaches such as supported employment can help individuals find and keep meaningful work, which not only has obvious financial benefits but also results in improved illness management, role functioning, and self-esteem [13]. VHA also offers two pre-employment programs, Transitional Work Experience (TWE) and Incentive Therapy (IT), as well as general vocational counseling, referred to as "vocational assistance." However, PTSD may be an impediment to employment, even in programs emphasizing work readiness rather than competitive employment such as TWE; Resnick and Rosenheck found that Veterans with PTSD were 19 percent less likely to be employed at discharge from the program than Veterans without PTSD and concluded that supported employment, which is primarily targeted to individuals with severe mental illness, may need to be modified to meet the needs of Veterans with PTSD [14]. Cognitive impairment, common among individuals with mental health conditions, appears to make navigating the pathways to vocational services offered by VHA difficult [15]. Veterans with a psychiatric disorder and sequelae of TBI, typically seen in VHA polytrauma clinics, may be most likely to experience cognitive barriers to entering vocational services. Further documentation of the effectiveness of supported employment with OIF/OEF Veterans is needed to gauge the importance of expanding the availability of this service to this new era of Veterans.

We had previously analyzed quality improvement data from 279 OIF/OEF Veterans at the Department of Veterans Affairs (VA) San Diego Healthcare System who had been referred to VHA vocational services between January 2006 and August 2009. Of these Veterans, only $126(45 \%)$ of those referred attended an orientation session, $41(15 \%)$ attended an intake interview, $24(9 \%)$ returned for a subsequent appointment, 11 (4\%) enrolled in supported employment (all Veterans with TBI taking part in a study that began in December 2008), and 4 (1\%) were placed in competitive employment. Because of the low rates of engagement in services and low utilization of evidence-based supported employment, we sought to investigate nationwide patterns of vocational service use among OIF/OEF Veterans with the top four mental health conditions. To our knowledge, no such national-level investigation had been undertaken. We hypothesized that OIF/OEF Veterans would have low rates of accessing and engaging in vocational services and low rates of participation in evidence-based supported employment, but that when provided, supported employment would result in 
high rates of competitive work. We also examined whether access and engagement in vocational services, as well as competitive work placement, was related to any demographic, financial, or clinical factors.

\section{METHODS}

The Northeast Program Evaluation Center (NEPEC) prepared deidentified databases using the VA Austin Information and Technology Center (AITC) data encounter files and OIF/OEF registry from fiscal years (FYs) 2008 and 2009 to ascertain the number of OIF/OEF Veterans with one or more of the top four mental health conditions (PTSD [International Statistical Classification of Diseases and Related Health Problems-9 (ICD-9) code 309.81], depressive disorders [ICD-9 codes 296.2, 296.3, 311], substance use disorder [ICD-9 codes 303.x-305.x], and sequelae of TBI [ICD-9 codes 310.x, 850-854]). The time frame of FYs 2008 to 2009 was chosen because the national-level database added an OIF/OEF identifier to their data starting in FY 2008 and because VHA clinical services increased their response to the needs of OIF/OEF Veterans during this time. Of this sample, we ascertained the proportion of referred Veterans who accessed any vocational rehabilitation services within VHA (i.e., had at least one service contact, or "encounter," under relevant VHA stop codes [568, 569, or 222 for supported employment; 570, 574, or 208 for TWE; 573 or 207 for IT; 575, 535,536 , or 213 for other vocational assistance]). We included 75,607 OIF/OEF Veterans who had a diagnosis of PTSD, depression/mood disorder, substance use disorder, or TBI sequelae in at least one inpatient record or at least two outpatient encounters within FYs 2008 or 2009 in the deidentified database, and all were assigned an identification number. Enrollment in TWE and supported employment was tracked using the stop codes for those services. Veterans who received a mixture of different services were classified as receiving the "highest" or most intensive level service they ever received, with supported employment considered to be the most intensive, followed by TWE, IT, and vocational assistance (e.g., a Veteran who received one supported employment encounter and two other types of service encounters was classified as receiving supported employment).

NEPEC collects client-level data on the CWT program as part of the performance monitoring of VA mental health programs (for further details, see Resnick and
Rosenheck [14]). NEPEC created a deidentified database of longitudinal work outcome data for all OIF/OEF Veterans who received NEPEC-tracked vocational services at any time during FYs 2008 and 2009. NEPEC assigned the same identification numbers to each Veteran as did AITC, so the two databases could then be linked. NEPEC data on Veterans who enroll in vocational services are completed by CWT clinicians via secure VHA intranet at time of enrollment and quarterly until discharge. Quarterly and discharge data are collected for the prior $90 \mathrm{~d}$. Variables included number of days worked in competitive employment for the past $90 \mathrm{~d}$, average number of hours worked per day, average wage earned per hour, and number of jobs or job placements in the past $90 \mathrm{~d}$. Length of enrollment in vocational services was determined by calculating the amount of time between the admission and discharge dates provided on the NEPEC forms.

We computed descriptive statistics and inferential tests such as $t$-tests and chi-square tests, along with their relevant effect sizes. We inspected all variables for normality and homogeneity of variance and made appropriate statistical adjustments for inferential tests of variables not meeting standard statistical assumptions.

\section{RESULTS}

Of the 75,607 OIF/OEF Veterans with diagnoses of PTSD, depression, substance use disorders, or TBI sequelae in FYs 2008 and 2009, 6,345 (8.4\%) had at least one vocational services encounter during that time. Note that it is not possible to ascertain how many Veterans were referred for vocational services because referrals are not tracked. Table 1 describes the total sample and shows demographic, clinical, and financial differences between those who did and did not have a vocational service encounter. All queried differences were statistically significant because of the large sample size, but interpretation of the relevant effect sizes (Cohen $d$ for $t$-tests and $\varphi$ for chi-square tests [16-17]) revealed that there were negligible effects of age, sex, or presence/amount of service-connected disability. Presence of PTSD, depression, or substance use disorder also had negligible effects on having a vocational encounter, but presence of TBI sequelae had a relatively strong association with having a vocational encounter. The strongest predictor of having a vocational encounter (with a medium to large effect size) was having a greater number of mental health diagnoses. 
JRRD, Volume 50, Number 5, 2013

Table 1.

Characteristics of Operation Iraqi Freedom/Operation Enduring Freedom Veterans with mental health conditions without and with vocational encounters in fiscal years 2008 and 2009.

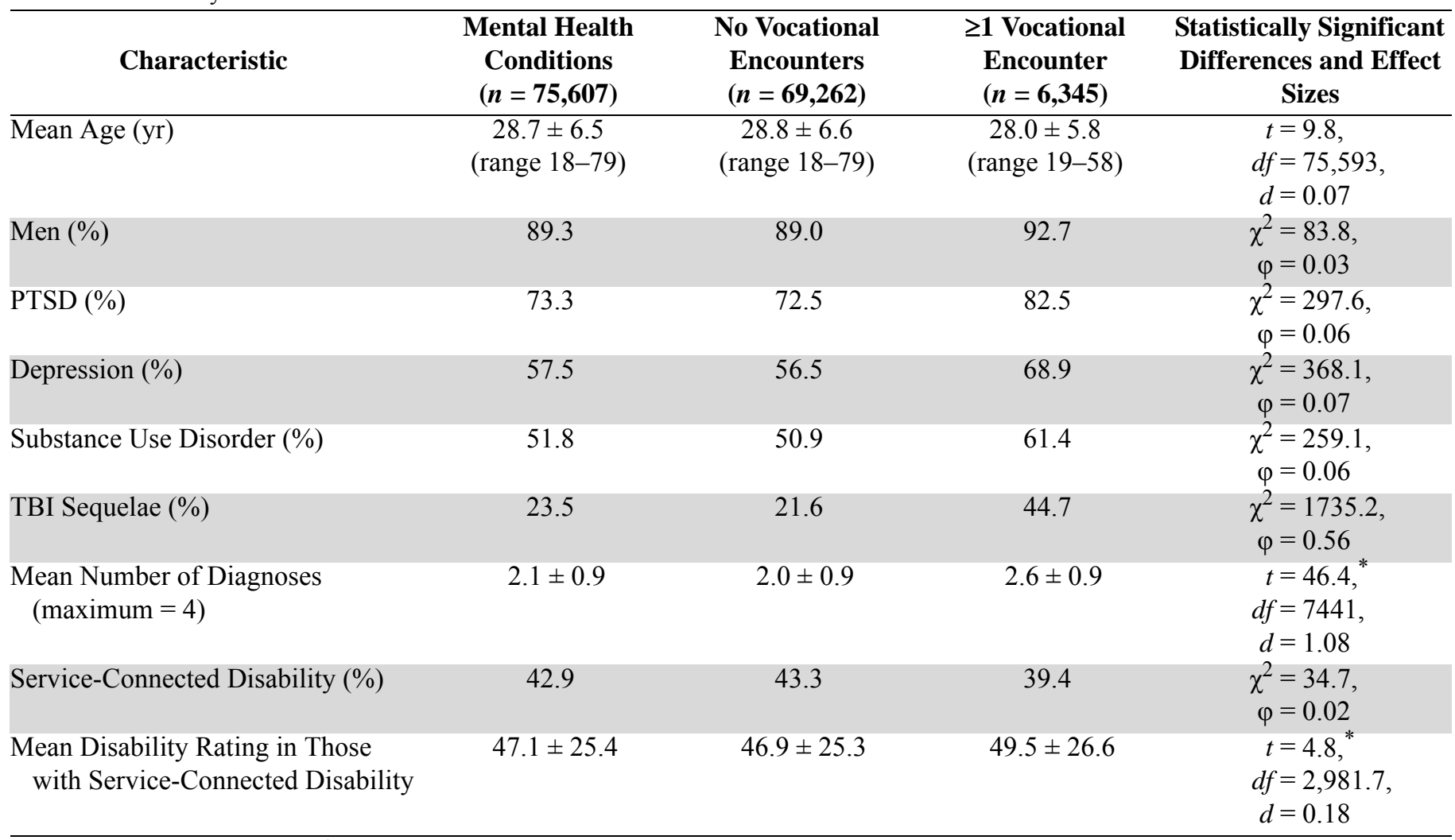

Note: Degrees of freedom $(d f)$ for $\chi^{2}=1$. All $p<0.001$.

${ }^{*} t$-test $d f$ adjusted because of unequal variances.

PTSD $=$ posttraumatic stress disorder; TBI $=$ traumatic brain injury.

Table 2 lists the percentages of Veterans receiving different types of vocational encounters, with the highest intensity service per Veteran counted. Of the 8.4 percent of Veterans with at least one vocational encounter, about one-fourth each received supported employment and TWE, and the remaining half received other vocational services. Within the 8.4 percent of Veterans with at least one vocational encounter, 40 percent had only one vocational encounter, 16 percent had two encounters, 9 percent had three encounters, 7 percent had four encounters, and 28 percent had five or more encounters in FYs 2008 and 2009.

Using the merged AITC-NEPEC database, we examined NEPEC-tracked work outcomes among all OIF/OEF Veterans with the mental health conditions of interest who were enrolled in NEPEC-tracked vocational programs at any point in FYs 2008 or 2009. There were $1,010 \mathrm{OIF} / \mathrm{OEF}$ Veterans in this sample, 79 percent with PTSD diagnosis, 76 percent with depression, 74 percent
Table 2.

Highest level vocational encounter type among 75,607 Operation Iraqi Freedom/Operation Enduring Freedom Veterans with mental health conditions in fiscal years 2008 and 2009.

Vocational Service Type Number (\%) with at

\begin{tabular}{lc}
\hline Supported Employment & $1,694(2.2)$ \\
Transitional Work Experience & $1,347(1.8)$ \\
Incentive Therapy & $138(0.2)$ \\
Other Vocational Service & $3,166(4.2)$ \\
No Vocational Service & $69,262(91.6)$ \\
\hline \hline
\end{tabular}

with a substance use disorder, and 37 percent with a TBIrelated diagnosis. We divided the sample into Veterans who had no supported employment encounters and those who had at least one supported employment encounter. Differences between these groups, presented in Table 3, demonstrated that rate of competitive work attainment, 
Table 3.

Competitive work outcomes among Northeast Program Evaluation Center (NEPEC)-tracked Operation Iraqi Freedom/Operation Enduring Freedom (OIF/OEF) Veterans with mental health conditions in fiscal years 2008 and 2009.

\begin{tabular}{|c|c|c|c|c|}
\hline Measure & $\begin{array}{c}\text { NEPEC-Tracked } \\
\text { OIF/OEF Veterans with } \\
\text { Mental Health Conditions } \\
(n=1,010)\end{array}$ & $\begin{array}{l}\text { No Supported } \\
\text { Employment Encounters } \\
\qquad(n=531)\end{array}$ & $\begin{array}{l}\geq 1 \text { Supported } \\
\text { Employment Encounter } \\
\qquad(n=479)\end{array}$ & $\begin{array}{c}\text { Test Statistic, } d f \text {, } \\
\qquad p \text {-Value, } \\
\text { and Effect Size }\end{array}$ \\
\hline $\begin{array}{l}\text { Obtaining Competitive } \\
\text { Work (\%) }\end{array}$ & $354(35)$ & $111(21)$ & $243(51)$ & $\begin{aligned} \chi^{2} & =98.4 \\
d f & =1 \\
p & <0.001 \\
\varphi & =0.31\end{aligned}$ \\
\hline Days Worked* & $133 \pm 150$ & $59 \pm 70$ & $167 \pm 164$ & $\begin{aligned} t & =8.7,^{\dagger} \\
d f & =350.7 \\
p & <0.001 \\
d & =0.86\end{aligned}$ \\
\hline Hours per Day ${ }^{*}$ & $7.3 \pm 1.5$ & $7.1 \pm 1.7$ & $7.5 \pm 1.4$ & $\begin{aligned} t & =2.1{ }^{\dagger} \\
d f & =183.6 \\
p & =0.03 \\
d & =0.25\end{aligned}$ \\
\hline $\begin{array}{l}\text { Days of Enrollment in } \\
\text { Vocational Services }\end{array}$ & $239 \pm 219$ & $170 \pm 137$ & $322 \pm 264$ & $\begin{aligned} t & =10.7 t^{\dagger} \\
d f & =603.0 \\
p & <0.001 \\
d & =0.72\end{aligned}$ \\
\hline
\end{tabular}

number of competitive jobs worked during CWT enrollment, cumulative number of days worked, average hours worked per day, and length of stay (in days) in vocational services were significantly higher for Veterans who had at least one supported employment encounter. There was a moderate association of having a supported employment encounter with obtaining competitive work $(51 \%$ of Veterans with at least one supported employment encounter worked competitively, compared with $21 \%$ of those who did not receive supported employment). There were large effects of having at least one supported employment encounter on the number of competitive jobs obtained and number of days worked and a mediumto-large effect size on the number of days enrolled in vocational services. Among those who worked competi- tively, supported employment encounter history had a negligible to small effects on average hourly wages and hours worked per day. Because those receiving supported employment had a longer length of stay in vocational services than those who did not receive supported employment, we conducted hierarchical regression analyses to assess whether receiving supported employment resulted in higher rates of competitive work and higher numbers of jobs and days in competitive work, even after controlling for length of stay in vocational services. In each case, length of stay in vocational services was entered in the first block and receipt of supported employment was entered in the second block. When length of stay was controlled for, receipt of supported employment remained a significant predictor of obtaining competitive 
work (Wald $=27.3, d f=1, p<0.001$ ), as well as total days of competitive work $(\beta=0.139, t[1007]=2.90, p<$ $0.004)$ and total number of competitive jobs $(\beta=0.095$, $t[1007]=1.97, p=0.05)$.

We also examined whether competitive job attainment among the NEPEC-tracked sample was related to demographic, financial, or clinical factors. Competitive work attainment was not related to sex, PTSD, depression, or TBI-related diagnosis (all $p>0.14$ ). Veterans with a substance use disorder diagnosis were less likely to work competitively ( $30 \%$ vs $49 \% ; \chi^{2}=29.6, d f=1, p<0.001$; $\varphi=0.17)$, and those with any level of service-connected disability were more likely to work competitively ( $42 \%$ vs $\left.31 \% ; \chi^{2}=12.3, d f=1, p<0.001 ; \varphi=0.11\right)$. However, the effect sizes associated with these results suggested only weak associations. Age $(t=2.4, d f=1008, p=0.02)$ and percentage of service connection $(t=2.5, d f=704.1, p=$ 0.01 ) also had negligible to small effects on competitive work outcomes, with those who were slightly younger or with a slightly higher percentage of service connection being more likely to work competitively.

\section{DISCUSSION}

Using a national-level database of 75,607 OIF/OEF Veterans with diagnoses of PTSD, depression, substance use disorders, or TBI sequelae in FYs 2008 and 2009, we found that only 8.4 percent of these Veterans had a vocational services encounter during that time. This is striking because we know that the unemployment rate among OIF/OEF Veterans is about 13 percent [5] and is suspected to be even higher among Veterans with mental health conditions. Thus, it is likely that less than half of OIF/OEF Veterans with mental health conditions who could benefit from vocational services are actually accessing these services. We also found that most Veterans who received any vocational service did not receive evidence-based services. Only 2.2 percent of Veterans received even one session of evidence-based supported employment, perhaps not surprising given that the target population for supported employment in the VA is individuals with symptoms of psychosis. Retention in vocational services was poor overall for those included in the current study; most Veterans who received any vocational service had only one or two encounters within FYs 2008 and 2009, which is not considered an intensive enough service to make job placement likely because vocational services typically take one to two sessions to complete an initial assessment [12].

Having a TBI-related diagnosis was strongly associated with having a vocational encounter, as was having a higher number of mental health conditions. Interactions between TBI sequelae and psychological health conditions may contribute to a downward spiral affecting occupational functioning [18]. OIF/OEF Veterans with multiple mental health conditions, but particularly those who also have a history of TBI and associated cognitive impairments, may face more barriers to workforce participation and may be among those most likely to seek VHA vocational services [15].

Despite the low rate of supported employment service provision, evidence-based supported employment was effective when it was provided. NEPEC-tracked work outcomes indicated that 51 percent of Veterans who received at least one supported employment visit went on to obtain competitive work, compared with 21 percent of Veterans who did not receive supported employment. Those receiving supported employment obtained more jobs, worked more days (an average of $167 \mathrm{~d}$ while enrolled in CWT), and engaged in vocational services longer than those who did not. The effect sizes associated with these differences were in the large range. It is likely that one of the reasons for supported employment's success is that it focuses on job development in the community with employers interested in hiring Veterans (as was recently discussed in the oversight hearing by the House Subcommittee on Veterans' Affairs [19]). In the sample of Veterans with work outcome data, demographic, clinical, and financial factors did not significantly affect work outcomes. This suggests that all unemployed Veterans with mental health conditions who want to return to the workforce, regardless of diagnosis or presence/level of service-connected disability, would benefit from supported employment.

Supported employment is an evidence-based treatment for people with severe mental illness, a population that was traditionally underserved; thus, current VHA supported employment guidelines reserve 75 percent of each employment specialist's caseload for Veterans who have a psychotic disorder. Most VHA facilities have one supported employment specialist, whose maximum caseload is 25 clients at any given time, in order to provide the service intensity required by the model. The new Homeless Veterans Supported Employment Program is available for Veterans who are homeless. This suggests that employment resources 
are limited for OIF/OEF Veterans without psychosis or homelessness. Given the success rate of supported employment in OIF/OEF Veterans without a psychotic disorder, additional supported employment specialists for this population would be expected to improve work outcomes for post-9/11 Veterans who need assistance returning to work. Increased return to work in this population might also have an indirect benefit of reducing homelessness.

Our study has several limitations. First, because referrals to vocational services are not tracked nationally, we do not know how many OIF/OEF Veterans with mental health conditions were referred to VHA vocational services. Based on local data at the VA San Diego Healthcare System, 45 percent of Veterans referred to vocational services attended an orientation session. We also were not able to assess how many Veterans were referred to vocational services outside VHA, such as in the Veterans Benefits Administration, which administers the Vocational Rehabilitation and Education program, which many Veterans use for assistance with the Post-9/11 GI Bill. Based on our large administrative data set, we also were not able to assess the potential barriers to engagement and retention of Veterans in vocational services. Further studies that gather the input of Veterans and staff members alike would be helpful in examining whether current VHA vocational services are meeting the needs of post-9/11 Veterans.

\section{CONCLUSIONS}

Given the results in published literature and our findings in this report, we are confident that recovery-oriented, evidence-based supported employment is the best way to assist unemployed OIF/OEF Veterans with mental health conditions to achieve competitive employment. However, given current staffing, supported employment is necessarily a service reserved mainly for Veterans with psychotic disorders (not commonly diagnosed in OIF/OEF Veterans [4]) or Veterans who are homeless. Possible solutions to increase access to supported employment for post-9/11 Veterans include hiring new supported employment specialists to serve this population or transitioning current resources that are not evidence-based (e.g., trainthen-place approaches such as sheltered workshops, incentive therapy) to provide evidence-based supported employment. Given that Veterans with TBI are particularly likely to need vocational services, supported employment could be effectively integrated into VHA polytrauma clinics, as has been done in some VHA facilities, as well other settings.

\section{ACKNOWLEDGMENTS}

\section{Author Contributions:}

Study concept and design: E. W. Twamley.

Analysis and interpretation of data: E. W. Twamley, S. G. Resnick,

D. G. Baker, S. B. Norman, J. B. Lohr, J. O. Pittman.

Drafting of manuscript: E. W. Twamley.

Critical revision of manuscript for important intellectual content:

E. W. Twamley, D. G. Baker, S. B. Norman, J. O. Pittman, J. B. Lohr, S. G. Resnick.

Financial Disclosures: The authors have declared that no competing interests exist.

Funding/Support: This material was based on work supported by the VA Health Services Research and Development Mental Health Quality Enhancement Research Initiative (grant RRP 10-052).

Additional Contributions: The authors thank Richard Kaczynski, $\mathrm{PhD}$, for his assistance with creating the data sets and the VA Office of Mental Health Operations Data Use Agreement Review Committee for their helpful review.

Institutional Review: The study was approved by the University of California, San Diego Institutional Review Board.

\section{REFERENCES}

1. Seal KH, Metzler TJ, Gima KS, Bertenthal D, Maguen S, Marmar CR. Trends and risk factors for mental health diagnoses among Iraq and Afghanistan veterans using Department of Veterans Affairs health care, 2002-2008. Am J Public Health. 2009;99(9):1651-58.

[PMID:19608954] http://dx.doi.org/10.2105/AJPH.2008.150284

2. Hoge CW, McGurk D, Thomas JL, Cox AL, Engel CC, Castro CA. Mild traumatic brain injury in U.S. Soldiers returning from Iraq. N Engl J Med. 2008;358(5):453-63. [PMID:18234750] http://dx.doi.org/10.1056/NEJMoa072972

3. Tanielian T, Jaycox LH, editors. Invisible wounds of war: Psychological and cognitive injuries, their consequences, and services to assist recovery. Santa Monica (CA): RAND Corporation; 2008.

4. Adler DA, Possemato K, Mavandadi S, Lerner D, Chang H, Klaus J, Tew JD, Barrett D, Ingram E, Oslin DW. Psychiatric status and work performance of veterans of Operations Enduring Freedom and Iraqi Freedom. Psychiatr Serv. 2011;62(1):39-46. [PMID:21209298] http://dx.doi.org/10.1176/appi.ps.62.1.39 
5. Economic news release, employment situation summary [Internet]. Washington (DC): Bureau of Labor Statistics; 2012 [cited 2012 Jan 6]. Available from:

http://www.bls.gov/news.release/empsit.t05.htm

6. Sturm R, Gresenz CR, Pacula RL, Wells KB. Datapoints: labor force participation by persons with mental illness. Psychiatr Serv. 1999;50(11):1407. [PMID:10543847]

7. Kuhn JH, Nakashima J. Community Homelessness Assessment, Local Education and Networking Group (CHALENG) for Veterans Fiscal Year (FY) 2010 [Internet]. Washington (DC): Services for Homeless Veterans Assessment and Coordination; 2011 [cited 2012 Jan 6]. Available from: http://www.va.gov/HOMELESS/docs/chaleng/ CHALENG Report Seventeenth_Annual.pdf

8. Bond GR, Becker DR, Drake RE, Rapp CA, Meisler N, Lehman AF, Bell MD, Blyler CR. Implementing supported employment as an evidence-based practice. Psychiatr Serv. 2001;52(3):313-22. [PMID:11239097]

http://dx.doi.org/10.1176/appi.ps.52.3.313

9. Bond GR, Drake RE, Becker DR. An update on randomized controlled trials of evidence-based supported employment. Psychiatr Rehabil J. 2008;31(4):280-90.

[PMID:18407876]

http://dx.doi.org/10.2975/31.4.2008.280.290

10. Twamley EW, Jeste DV, Lehman AF. Vocational rehabilitation in schizophrenia and other psychotic disorders: a literature review and meta-analysis of randomized controlled trials. J Nerv Ment Dis. 2003;191(8):515-23.

[PMID:12972854]

http://dx.doi.org/10.1097/01.nmd.0000082213.42509.69

11. Resnick SG, Rosenheck R. Dissemination of supported employment in Department of Veterans Affairs. J Rehabil Res Dev. 2007;44(6):867-77. [PMID:18075943] http://dx.doi.org/10.1682/JRRD.2007.02.0043

12. Becker DR, Drake RE. A working life for people with severe mental illness. New York (NY): Oxford University Press; 2003.

13. Becker D, Whitley R, Bailey EL, Drake RE. Long-term employment trajectories among participants with severe mental illness in supported employment. Psychiatr Serv. 2007;58(7):922-28. [PMID:17602007] http://dx.doi.org/10.1176/appi.ps.58.7.922
14. Resnick SG, Rosenheck RA. Posttraumatic stress disorder and employment in veterans participating in Veterans Health Administration Compensated Work Therapy. J Rehabil Res Dev. 2008;45(3):427-35. [PMID:18629751] http://dx.doi.org/10.1682/JRRD.2007.06.0093

15. O’Connor MK, Mueller L, Van Ormer A, Drake R, Penk W, Rosenheck R, Semiatin A, Drebing CE. Cognitive impairment as barrier to engagement in vocational services among veterans with severe mental illness. J Rehabil Res Dev. 2011;48(5):597-608. [PMID:21674409] http://dx.doi.org/10.1682/JRRD.2010.06.0117

16. Cohen J. Statistical power analysis for the behavioral sciences. 2nd ed. New York (NY): Lawrence Erlbaum Associates; 1988.

17. Rea LM, Parker RA. Designing and conducting survey research. San Francisco (CA): Jossey-Bass; 1992.

18. Hoffman SW, Harrison C. The interaction between psychological health and traumatic brain injury: a neuroscience perspective. Clin Neuropsychol. 2009;23(8):1400-15. [PMID:19882478] http://dx.doi.org/10.1080/13854040903369433

19. CWT program helps wounded veterans adjust to civilian employment [Internet]. Washington (DC): House Committee on Veterans' Affairs; 2011 [cited 2012 Jan 6]. Available from:

http://veterans.house.gov/press-release/cwt-programhelps-wounded-veterans-adjust-to-civilian-employment

Submitted for publication August 1, 2012. Accepted in revised form November 14, 2012.

This article and any supplementary material should be cited as follows:

Twamley EW, Baker DG, Norman SB, Pittman JO, Lohr JB, Resnick SG. Veterans Health Administration vocational services for Operation Iraqi Freedom/Operation Enduring Freedom Veterans with mental health conditions. J Rehabil Res Dev. 2013;50(5):663-70.

http://dx.doi.org/10.1682/JRRD.2012.08.0137

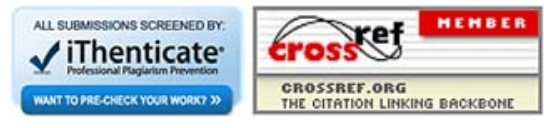

